\title{
KINESICS INTERACTION: TOWARDS EYE CONTACT, POSTURE AND FACIAL EXPRESSION OF EDWARD AND BELLA IN A MOVIE ENTITLED “TWILIGHT”
}

\author{
Made Chintya Maha Yekti \\ Ganesha University of Education \\ e-mail: chintyamahayekti23@gmail.com
}

\begin{abstract}
This study discusses the nonverbal communication particularly body language. This study focuses on kinesics such as: eye contact, posture, and facial expression of the male main character (Edward Cullen) and the female main character (Bella Swan) in Twilight movie by Stephenie Meyer. The aims of this study is to know the meaning behind those nonverbal communications of male main character and female main character as their acting in the movie. The method used to answer the problem of this study is Descriptive qualitative. The data of this study is a film entitled Twilight produced in 2008. The data is described in the form of images and words. From this study, it can be seen that there are three kinds of nonverbal communication used by the male and female main character. Those are eye contact, posture, and facial expression where the nonverbal communication used by the male character is concerned, serious, brave, romantic, cool postures, friendly and bright eyes. Whereas the female character uses dim eye contact, glace and shock posture, and amazed facial expression. It is found that there are several differences of using nonverbal communication between male and female character in the movie.
\end{abstract}

Keywords: nonverbal communication, eye contact, posture, facial expression, gender

\section{INTRODUCTION}

Research by Leva, Mtodagme, Peace (2017) concentrated on the study of nonverbal communication in the Nigerian mass media particularly in print advertising with two theories namely semiotics and structuralism theory in which they claimed that nonverbal communication is important to convey emotional, intellectual and informational meanings to audiences. Their study demonstrates illustrations from the Nigerian print advertising. They found that print advertisements often contain visuals which are indexical or symbolic signs of positive attributes that may be associated with the product on promotion. Therefore the nonverbal language that is used can support the advertisement in promoting the products.

Another research by O'Reilly (2012) from University of Gothenburg Sweden, also analyzes the bipedics gesture or the new category of kinesics. In that research he just focuses on the expression of attitude, and emotion, through simple leg and foot gesture. He uses mannequin dolls to interpret the interaction. The results from His study support a link between certain bipedic gestures and the expression of attitudes and emotions. It was ecpected that the findings of the study stimulate further research on this neglected part of the human body and its communicative affordances.

The same kind of research was conducted by Windayanti \& Suwono (2014) who analyze the facial expressions and gestures of body language of the male main character Jack McCall in "A Thousand Words" film. The purpose of their study was to know the meaning behind facial expressions and gestures of the male main character Jack McCall as a representation of them which are expressed by people around the world. They used descriptive 
qualitative as a method in answering the problems of the study.

In this study, the researcher will use a movie as the source of data. The researcher believes that in learning a foreign language, watching foreign movies exposes people in the target language to the way people in native language actually speak. Movies also simultaneously address different senses and cognitive channels. For instance, spoken language is supported by visual elements that make it easier for people who learn target language to understand the dialogues and the plot. Instead of verbal cues, non-verbal cues are more important than verbal elements in any communication (Leva, Mtodagme, \& Peace, 2017). This is in line with the fact that nonverbal communication is central to effective expression or communication of ideas. Nonverbal communication expresses meaning or feeling without using any words, for instance using gesture, eye contact, face expression, etc (Levine \& Adelinan, 1982).

Realizing that nonverbal communication is also important in any communication and interaction, this study will use the same theories with the previous study that is kinesics theory. The aim of the study is to find out what kinds of gesture (non-verbal) communication that is used by the actor (Edward Pattison) and the actress (Bella Swan) in "Twilight". As we know male and female have different style in various activities, especially in communication system. Through this study, it is greatly hoped that people can understand the culture of the other countries especially how male interacts with female by watching foreign movies (Western movies) therefore misunderstanding can be avoided between the differences of male and female styles in communication especially in nonverbal communication.

This study describes the non-verbal communications express by the characters Edward Cullen and Bella Swan in Twilight movie.

\section{LITERATURE REVIEW}

Definition of Nonverbal Communication

According to Larry A. Samovar in (Wang, 2009), "nonverbal communication involves all those nonverbal stimuli in a communication setting that are generated by both the source and his or her use of the environment and that have potential message value for the source or receiver." There is no any word in nonverbal communication. It just uses nonverbal stimuli to interact between both the source and the receiver. Abercrombie (1968: 55) in (Surkamp, 2014), states that what is generally taken for granted: "We speak with our vocal organs, but we converse with our entire bodies." Abercrombie tries to state that body also says something and can express the information the same line with the word that we speak. Every facial expression and every gesture contributes to the overall meaning of a statement. Our body language accompanies every speech act we make, and even if we do not speak, our nonverbal behavior constantly transmits information that can be meaningful.

Calero as cited by (Windayanti \& Suwono, 2014) states that humans have capability of receiving information besides what is written or spoken (2005: 1). It means humans have another capability in communication. It calls as nonverbal communication in which people communicate using their body movements as a symbol or a signal while speaking. Body language is a universal language which is expressed by people around the world. Nonverbal communication has been used as a primary communication tool since thousands years ago. Calero as cited by (Windayanti \& Suwono, 2014) explains that for thousands of years, mankind has used wordless messages to communicate, thoughts, attitudes, ideas, and emotions, by using gesture, posture, facial expressions, sounds, and symbols (2005: 2).

Hans \& Hans (2015) stress on three aspects of nonverbal communication. The three main aspects of nonverbal communication are kinesics, haptic and proxemics.

1. Kinesics comes from the root word kinesis, which means "movement," and refers to the study of hand, arm, body, and face movements. According to Marcel Danesi as cited by (Windayanti \& Suwono, 2014) kinesics is body language that is used to indicate communication by means of gestures, postures, and other witting and unwitting body signals 
and signs (2004: 53). According McNeill as cited by (Windayanti \& Suwono, 2014), he said "gestures I mean are everyday occurrences spontaneous, unwitting, and regular accompaniments of speech that we see in our moving finger, hands, and arms (2005: 3)". This section will outline the use of eye contact, posture and facial expression.

a. Eye Contact.

Eyes are the window of the soul. We can see the people expression by seeing their eyes. The saying "Your mouth can lie but your eyes do not" is actually accurate in terms of communication. The face and eyes are the main point of focus during communication, and along with our ears our eyes take in most of the communicative information around us. Eye contact serves several communicative functions: to monitoring interaction, to conveying information, to establishing interpersonal connections, (Hans \& Hans, 2015).

In terms of regulating communication, we use eye contact to signal to others that we are ready to speak or we use it to cue others to speak. During an interaction, eye contact also changes as we shift from speaker to listener. Our eyes bring in the visual information we need to interpret people's movements, gestures, and eye contact. Making eye contact with others also communicates that we are paying attention and are interested in what another person is saying. Eye contact can also be used to intimidate others.

\section{b. Posture}

Posture means "an attitude or position of body". Each movement of body has expressive $\&$ defensive functions. And the way of we sit or stand, walk in walk out tells a lot about us. Commonly, a good posture indicates confident attitude. There are four general human postures: standing, sitting, squatting, and lying down (Hans \& Hans, 2015)

\section{c. Facial Expression}

Our faces are the most expressive part of our bodies. Think of how photos are often intended to capture a particular expression. Even though a photo is a snapshot in time, we can still interpret much meaning from a human face caught in a moment of expression. From facial expression we can interpret the feeling of happiness, sadness, fear, anger, and disgust (Hans \& Hans, 2015). Our faces are the most expressive part of our body and can communicate an array of different emotions. When delivering something light-hearted or humorous, a smile, bright eyes, and slightly raised eyebrows will nonverbally enhance our verbal message, when delivering something serious or somber, a furrowed brow, a tighter mouth, and even a slight head nod can enhance that message.

2. Haptic is how touch has the power to comfort someone in moment. This positive power of touch is countered by the potential for touch to be threatening because of its connection to sex and violence. To learn about the power of touch, we turn to haptics, which refers to the study of communication by touch. A lack of nonverbal communication competence related to touch could have negative interpersonal consequences; for example, if we don't follow the advice we've been given about the importance of a firm handshake, a person might make negative judgments about our confidence or credibility. Touch is necessary for human social development, and it can be welcoming, threatening, or persuasive.

3. Proxemics refers to the study of how space and distance influence communication. We only need look at the ways in which space shows up in common metaphors to see that space, communication, and relationships are closely related. For example, when we are content with and attracted to someone, we say we are "close" to him or her. When we lose connection with someone, we may say he or she is "distant."

Specifically, this research will focus on the kinesics theory by Hans \& Hans (2015). In which the writer briefly wants to outline the use of eye contact, posture, and facial expression as nonverbal communication of the male (Edward Cullen) and female (Bella Swan) character in western movie entitled "Twilight".

\section{Male and Female Nonverbal Communication}

The study of gender is important to the study of language itself, and the first step to 
study gender is to explore the difference between male and female (Xia, 2013). It is quite clear that men and women have a lot of differences in many fields, for instance in their communication. Gender differences in communication have received a lot of attention due to the popularity of best-selling books such as Men Are from Mars, Women Are From Venus (Gray 1992) and You Just Don't Understand: Women and Men in Conversation (Tannen 1990), (McQuisto \& Morris, 2009).

The differences between genders communications begin during childhood. Girls are different with boys. It can be seen from their daily interaction. Girls are told to use their manners, play quietly, and be ladylike. However it is okay for boys to use rough language, play loudly, and be rambunctious. Girls are allowed to show feelings. For example, if a small girl scrapes her knee and starts to cry, she is nurtured. If a boy has the same minor injury, he is told not to cry and be tough. Hence girls develop a relational style of interaction whereas boys develop a competitive style of interaction (Mohindra \& Azhar, 2012).

\section{Uses of Nonverbal Communication}

Nonverbal communication is the other way to communicate with other, although in this interaction people do not use any words to interpret the meaning, the receivers already know the meaning itself. It is better to choose several common nonverbal behaviors to expound how nonverbal communication affects interpersonal communication. Sometimes, nonverbal communication also helps us to understand the meaning of things. For common example, if we want to say "NO" to the foreigner that we never meet before, we just need to shake of the head to them. Besides that, non-verbal cues are more important than verbal elements in any communication (Leva, Mtodagme, \& Peace, 2017). This is in line with the fact that non-verbal communication is central to effective expression or communication of ideas. Nonverbal communication expresses meaning or feeling without using any words, for instance using gesture, eye contact, face expression, etc (Levine \& Adelinan, 1982).
This study try to look at the nonverbal expression of Edward Cullen and Bella Swan in the Twilight movie.

\section{METHOD}

The method used in this study is descriptive qualitative method in which the researcher analyze the nonverbal language that is expressed by the actor (Edward Cullen) and the actress (Bella Swan) in the movie entitled "Twilight".

This descriptive qualitative method means researcher describes about what actually happen to procedures about method which are useful in research, or it can be also said that descriptive analysis is used to describe the basic features of the data in a study. The goal of qualitative descriptive study is a comprehensive summarization, in everyday terms, of specific events experienced by individuals or groups of individuals (Lambert \& Lambert, 2012). It is an approach that is very useful when researchers want to know, regarding events, who were involved, what was involved, and where did things take place.

From the definition, it can be said that qualitative research would be appropriate to be used in finding, analyzing, and presenting the data of the research in a more detailed way.

\section{Research Instrument}

The main instrument of this research is the researcher herself. The researcher will directly observe the nonverbal communication of the male character and the female character in the movie entitled "Twilight". The researcher analyzes the interaction of nonverbal communication in order to find out the differences of nonverbal communication that is used by different gender and to find out what nonverbal communication that they use while communicating with each other.

\section{Source of Data}

The source of data used in this study is a western movie entitled "Twilight". The source of the data is created by Stephenie Meyer, a novelist and producer from America. This movie entitled twilight was produced in 2008. 


\section{Data Collection Method}

The researcher uses study document and record method as the way of collecting the data. Here are several steps which are done by the researcher in order to observe the nonverbal communication in the movie entitled "Twilight" by Stephenie Meyer. First, the researcher watches the movie entitled "Twilight". Second, the researcher selects and analyzes the nonverbal communication that is used by the actor and the actress in the movie which belong to kinesics (eye contact, posture, and facial expression). Third, the researcher screens shoot the scene that showed nonverbal communication of male and female character. The fourth the researcher writes down the result of the analysis. And the last, the data is arranged based on its classification.

\section{Technique of Data Analysis}

In analyzing the data, here are several steps which are followed by the researcher:

1. Identification

The data which has collected by the researcher is identified based on the kinds of nonverbal communication (eye contact, posture, and facial expression) that exist in "Twilight" movie and then it is also focusing on the differences of nonverbal communication that is used by the actor (Edward Cullen) and the actress (Bella Swan).

\section{Classification}

The researcher classifies every nonverbal communication which is found in each interactions of the male and female character in the movie entitled "Twilight" by Stephenie Meyer based on the kinesics theory stated by Hans \& Hans (2015).

\section{Data Analysis}

The data of this study was analyzed by using descriptive qualitative analyzes. After the researcher found the nonverbal communication that is used by the actor (Edward Cullen) and the actress (Bella Swan) in the movie entitled "Twilight", the researcher classified the nonverbal communication based on three main categories. They are eye contact, posture, and facial expression. This kind of analysis was used to know what nonverbal communications that are used by the male and female character while communicating with each other and to know the differences of nonverbal communication that is used by the different gender in the western culture by watching the "Twilight" movie. The result of the data analysis will be presented in the form of paragraphs of each document or pictures of the nonverbal communication's scene.

\section{FINDINGS AND DISCUSSION Findings}

This part showed the result of the data analysis which has been conducted by the researcher in order to find out nonverbal communication that are used by the actor (Edward Cullen) and the actress (Bella Swan) in the movie entitled "Twilight" and also to find out the differences of nonverbal communication that are used by the actor and the actress.

1. Nonverbal communication that is used by the male character (Edward Cullen) and the female Character (Bella Swan) in the movie entitled "Twilight".

a. The Use of Eye Contact

The use of eye contact as nonverbal communication of the actor and the actress in this film can be seen in figure 1. This scene took place when the actor (Edward Cullen) met the actress (Bella Swan) for the second times. 


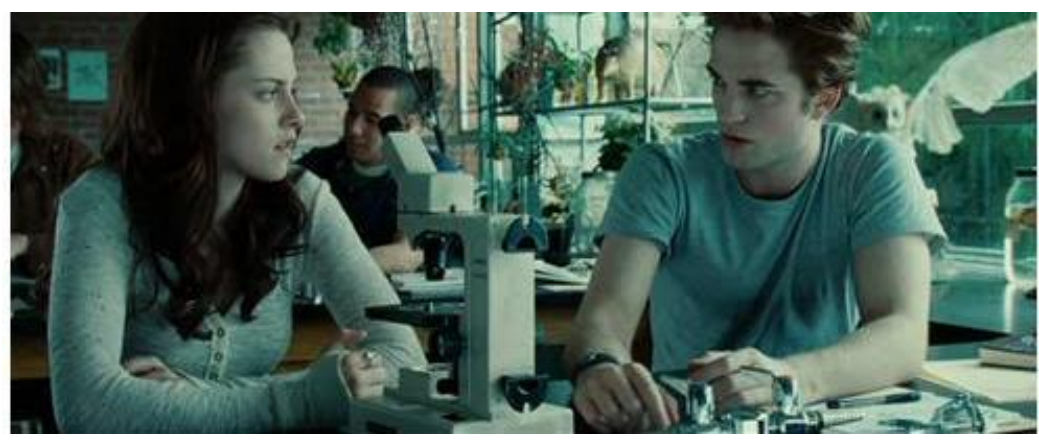

Figure 1. Edward met Bella for the second time

From Figure 1, it can be seen that the male character uses brief eye contact to the female character. The male character stares into the female's eyes while they were having conversation. The man character combined his eye contact with bending his eyebrows briefly. It signals a serious or curiosity. Social context of his gesture is that Edward Cullen as the man character tends to use this eye contact to get some information related to the female character, Bella Swan. It is also proved that the male character,Edward Cullen has a great curiosity. The female character on the other hand uses dim eye contact while talking to the male character. She also combined her dim eye contact with gaping lips. It proves that the female character wonder with the man character expression towards his eye contact. And it also proved that the female character hesitates to answer the male character's questions.

\section{b. The Use of Posture}

The use of posture of the male and female character in "Twilight" movie can be seen in the Figure 2, Figure 3 and Figure 4. Figure 2 and 3 are taken from the part when the female character (Bella Swan) knows the real information about the male character (Edward Cullen) that is the male character is a "Vampire". But the female character did not care about the truth although the male character has told the female character that he is a dangerous "Blood Monster". While Figure 4 is taken from the part when Edward tells his "Vampire" family to the female character (Bella Swan).

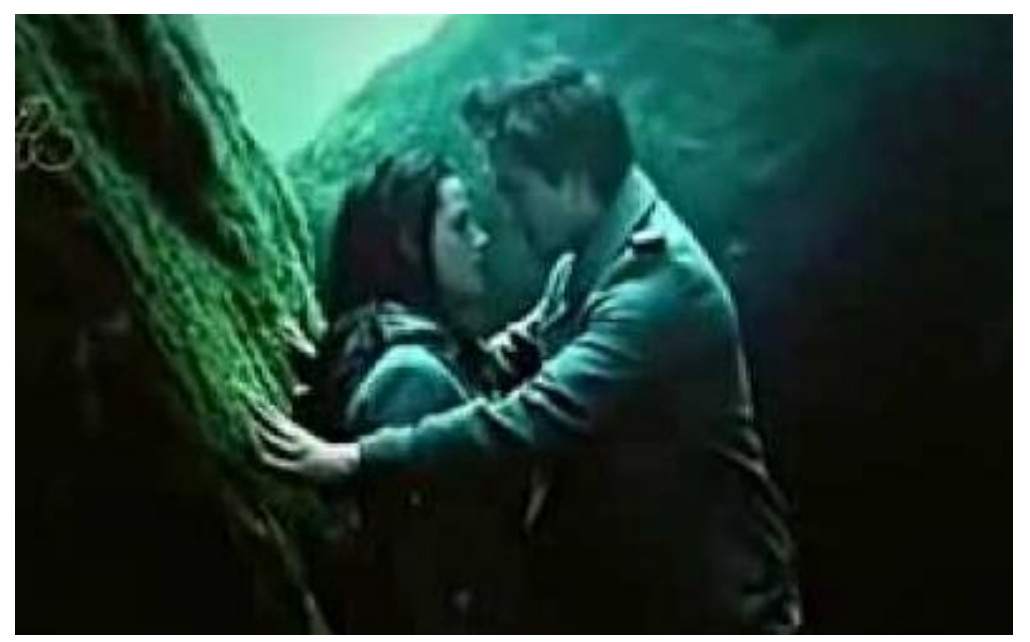

Figure 2. Bella found out that Edward was a monster 


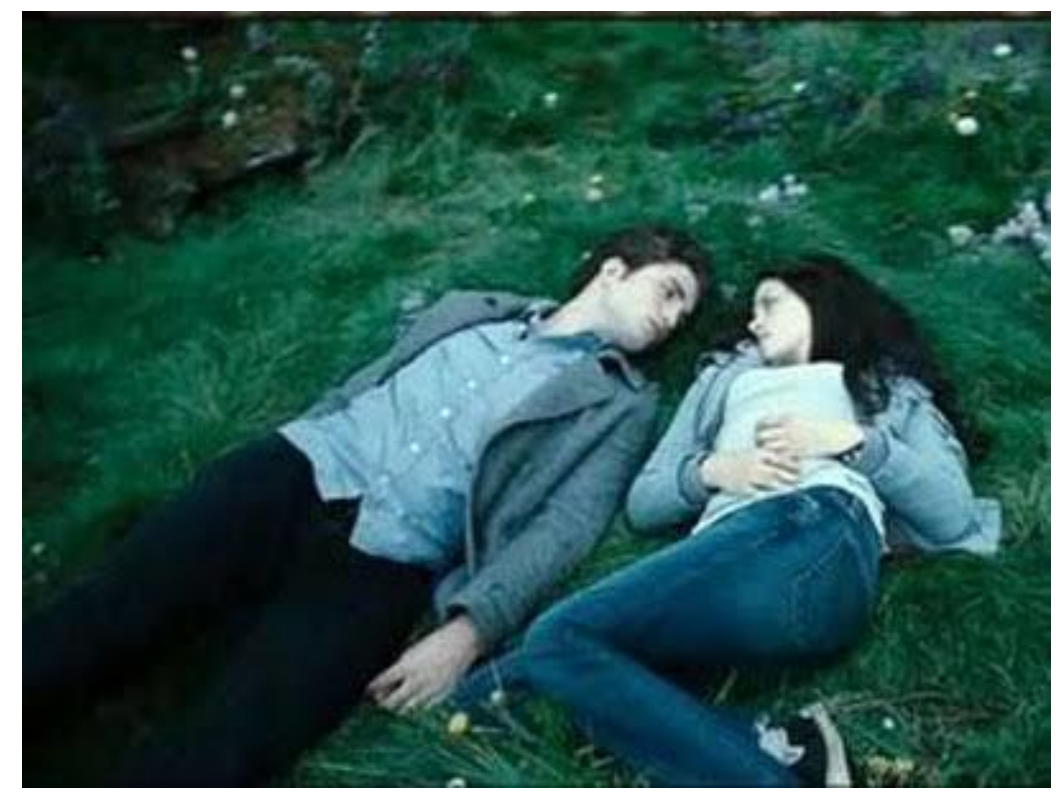

Figure 3. Bella found out that Edward was a monster

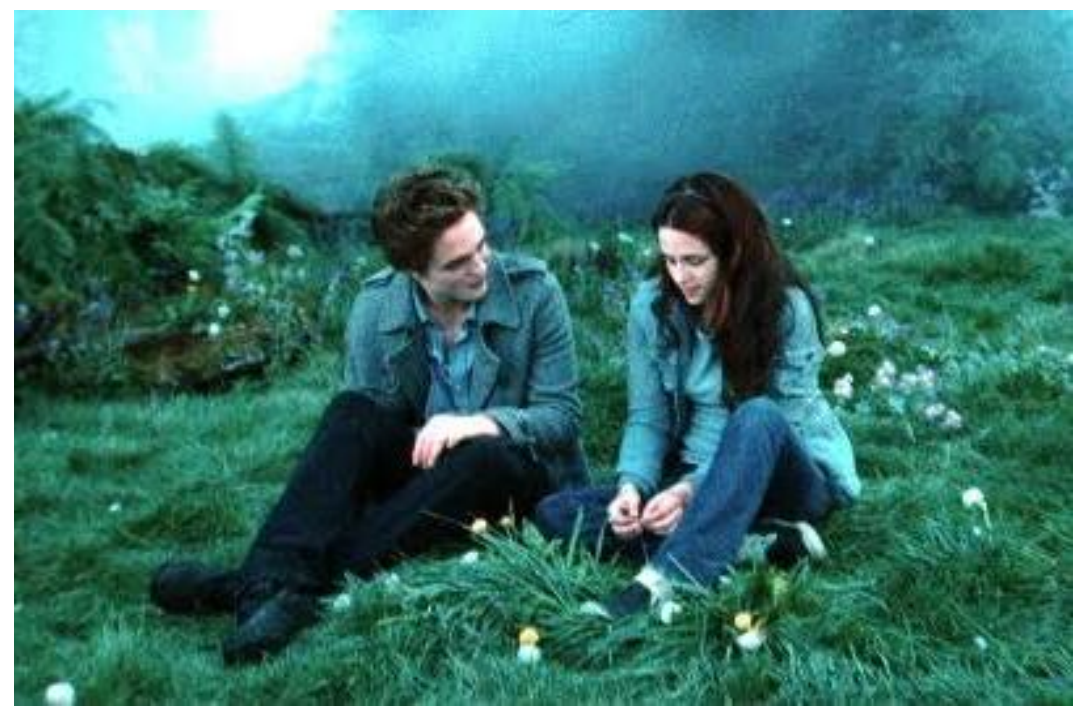

Figure 4. Edward telling about his family

Those figures represent posture as the nonverbal language used by the female and male character in the movie entitled "Twilight". From both figures, the second and the third figure can be seen that the male's posture is braver than the woman's posture. The second figure consist of: touching behavior, sticking arms together between the object, and arms sticking parallel to the body. People mostly use a hand gestures while they communicate and interact with others. People spontaneously move their hand to emphasize what they are trying to say to others. On the second figure, the male character is sticking his arms together between the female character. It can be seen that the male character in the movie entitled "Twilight" are serious, brave, and concerned. The third figure is on the other hand, consists of: the hand gestures. The male character looks so cool with his posture in which putting his arms together near his body. While the female character on the second figure looks so glace and shock while the man character stick his arms together between her. From that figure, it can be seen that the female character feels uncomfortable with that situation. While on the third figure, the female character looks so relax. It can be seen from her hands and her legs. She 
puts her arms together above her stomach, that proved that the female character was confortable with the situation. Meanwhile, the fourth figure is representing about leg gestures that consist of: crossed leg. The way of sitting can measure how deep people interest in a conversation. Both actor and actress used a common leg gesture that reveals their true feeling to their partners. Because, when people are involved in a conversation, they usually put their feet unconsciously into the conversation. After watching this scene, the man character tends to sit like this at the scene. It means that he has a good conversation and so does the female character, their legs indicates that they are sitting very relax during the scene. In this scene, Edward Cullen who is sitting by legs cross knee-knee position is wanted to get more attention from Bella Swan. While the conversation between Jack McCall and shrink in the research by Windayanti \& Suwono (2014) shows that Jack McCall also does that kind of sitting position. Legs and feet are an important source of information about someone's attitude because most people are unaware of what they are doing with them and never consider faking gestures with them in the way that they would with their face.

\section{c. The Use of Facial Expression}

The use of facial expression in the movie entitled "Twilight" can be seen in this scene, when they met in the biology class. At that time, the male character introduces himself to the female character. This figure will represent the use of facial expression by the male character (Edward Cullen) and the female character (Bella Swan).
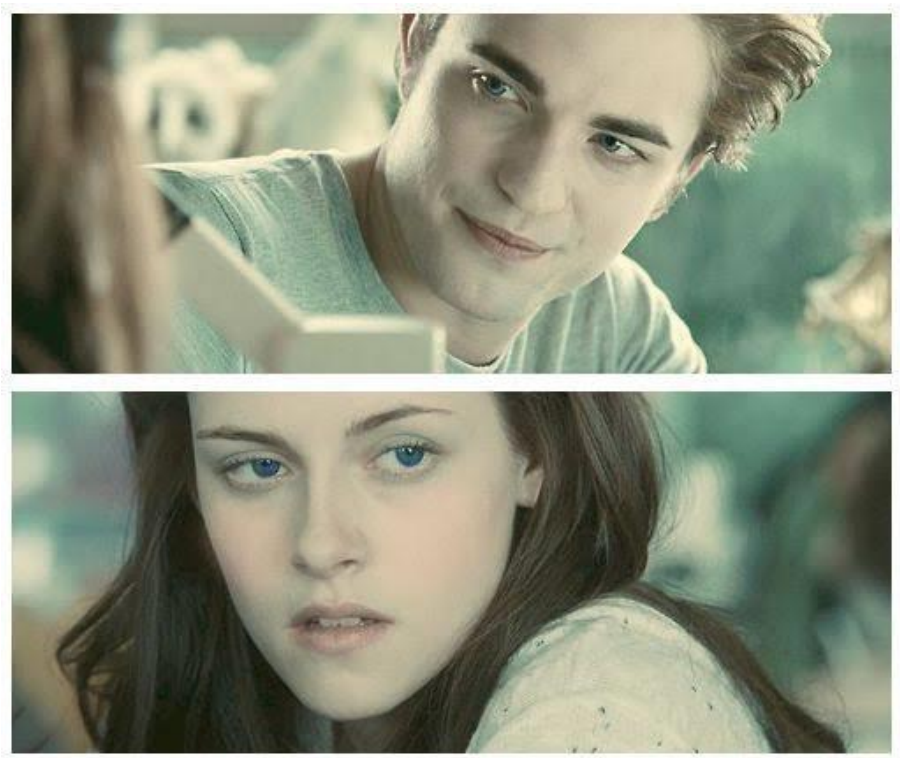

Figure 5. Edward and Bella met in a Biology class

That figure represents the facial expression of the male character and the female character on their second meeting. The male character is smiling on that scene. Smiling is the way the male character (Edward Cullen) emphasizes his feeling of happiness. Edward Cullen expresses upper smile when he is introducing himself to Bella Swan. And so does Jack McCall in research by Windayanti \& Suwono (2014). This upper smile shows a signal of respecting and welcoming. Edward Cullen gives an appreciation by showing his smiling to Bella at the first meeting. This facial expression shows a positive impression to the other character or the interlocutor. The interlocutor does not get insulted by Edward Cullen's facial expressions. By smiling and his bright eyes, it tells the female character that he is not threatening and asks the female character to accept his dialogue and answer his question. 
This is why smiling is important to have as a part of our body language. Because smiling directly influences other's people attitudes and how they respond to you. The female character on the other hand, she looks so amazed with the male character. It can be seen that from her eyes and also her lips which are opened a little. d. The Differences between Nonverbal Communication That is Used by The Male character (Edward Cullen) and the Female Character (Bella Swan). This analysis will be presented in Table 1.

Table 1. The Differences of Nonverbal Communication between the Male and Female Characters

\begin{tabular}{clll}
\hline \multirow{2}{*}{ Characters } & Eye contact & Posture & Facial Expression \\
\hline Edward Cullen & Brave & Serious & Smiling \\
& Staring & Brave & Bright Eyes \\
& Concerned & Romantic & \\
& & Cool & \\
Bella Swan & Dim Eye & Glace & Amazed \\
& & Shock & Lips open \\
& & confortable & \\
\hline
\end{tabular}

From the Table 1, it can be seen that there are several differences of male and female nonverbal communication in their interaction. Sometimes, male uses brave and staring eyes while talking to female. And the male also can be calm and romantic in using their body language, without saying any other words. Commonly, male is known as brave and serious human beings. But that is not always the case. Male can do both serious and calm depends on the situation. And so does the female character. Female is not always brave, sometimes women can be so calm and feminism. From this analysis it can be seen that female is more emotional than male because sometimes female change their feeling directly.

\section{DISCUSSION}

This part emphasizes about the data that have been found and analyzed by the researcher. As what has been stated in this findings that after analyzing the data in the movie entitled "Twilight" by Stephenie Meyer, the researcher found out that there are several non verbal communication that are used by the male character and the female character, especially for kinesics interaction such as: eye contact, posture, and also facial expression. There are also several differences in using nonverbal communication between male and female character in that movie.

Furthermore from the analysis of the data, especially about the nonverbal communication of both actor and actress of the movie entitled "Twilight", this movie actually use some nonverbal communication to make the movie viewer understand about their acting, therefore they use different nonverbal communication in their interaction. Besides, the actor and the actress use different nonverbal communication. That is influenced by the different gender. As already been told in the literature review, the different gender has their differences in many ways, for instance in using their nonverbal communication. From this analysis, it can be seen that the male and female character in "Twilight" movie have their differences, such as in using their eye contact, posture, and also the facial expression. The first result analysis is about the eye contact. The male character (Edward Cullen) uses brave and staring eye contact while talking with the female character (Bella Swan), while the female character uses dim eye contact in her interaction with the male character. The second is in using the posture. The male character uses serious, brave, romantic and cool posture in his interaction. The female character on the other hand, she uses glace and shock posture, but 
sometimes the female character uses confortable posture in some scenes. Tthe last is the facial expression. The male character uses smiling and bright eyes and the female character uses amazed and eyes and lips are opened to show her expression towards the male character.

\section{CONCLUSION}

The male character (Edward Cullen) and the female character (Bella Swan) in the movie entitled "Twilight" by Stephenie Meyer use three kinds of nonverbal communication in their interaction. In which those nonverbal communication belong to kinesics theory by Hans \& Hans (2015), those three kinds of nonverbal communication that are used by the male and female character are eye contact, posture, and facial expression. In which nonverbal communication that is used by male character is brave and staring eye contact, serious, brave, romantic and cool postures, and facial expression of smiling and bright eyes. Whereas the female character uses dim eye contact, glace and shock posture, and amazed facial expression. From that analysis there is also found several differences of using nonverbal communication between male and female character in the movie entitled "Twilight". Those nonverbal communication differences are influenced by the different gender.

Furthermore, by watching western movie it can help us to understand what kinds of nonverbal communication that is used by western people. People can understand the culture of the other countries especially how male interacts with female by watching foreign movies (Western movies). Therefore, misunderstanding can be avoided.

\section{REFERENCES}

Brock-Utne, B. (2005). The Interrelationship between Language and Culture. The Interrelationship between Language and Culture, 1-3.

Hans, A., \& Hans, E. (2015). Kinesics, Haptics and Proxemics: Aspects of Non -Verbal Communication . IOSR Journal of
Humanities And Social Science (IOSRJHSS) , 47-48.

Lambert, V. A., \& Lambert, C. E. (2012).

Qualitative Descriptive Research: An

Acceptable Design . Pacific Rim

International Journal of Nursing Research , 255-256.

Leva, V. A., Mtodagme, T. S., \& Peace, N. V. (2017). Nonverbal Communication as a Key Feature of the Nigerian Print Advertising Text. International joulnal of Information and Communication and Sciences, 1-2.

Levine, D. R., \& Adelinan, M. B. (1982). Nonverbal Communication. In D. R. Levine, \& M. B. Adelinan, Beyond Language (pp. 43-37). United States of America: Prentice-Hall.

McQuisto, D. H., \& Morris, K. A. (2009). Gender Differences in Communication: Implications for Gender Differences in Communication: Implications for Gender Differences in Communication: Implications Gender Differences in Communication: Implications for Salespeople . Journal of Selling \& Major Account Management , 54-58.

Mohindra, P. V., \& Azhar, D. S. (2012). Gender Communication: A Comparative Analysis of Communicational Approaches of Men and Women at Workplaces . IOSR Journal of Humanities and Social Science (JHSS) , 18.

O'Reilly, P. (2012). Bipedics: Towards a new category of kinesics. An empirical investigation of the expression of attitude, and emotion, through simple leg and foot gesture. Proceedings of the 4th Nordic Symposium on Multimodal Communication , 31-38.

Surkamp, C. (2014). Non-Verbal Communication: Why We Need It in Foreign Language Teaching and How We Can Foster It with Drama Activities. Scenario , 1-2.

Wang, H. (2009). Nonverbal Communication and the Effect on Interpersonal Communication. Asian Social Sience, 23. 
Windayanti, R. R., \& Suwono. (2014). FACIAL EXPRESSIONS AND GESTURES OF BODY LANGUAGE ANALYSIS OF THE MALE MAIN CHARACTER JACK MCCALL IN A THOUSAND WORDS FILM 2012. English Language and Literature Journal , 1-5.

Xia, X. (2013). Gender Differences in Using Language. Theory and Practice in Language Studies , 1-3. 